\title{
Tissue-Infiltrating Lymphocytes as a Predictive Factor for Recurrence in Patients with Curatively Resected Colon Cancer: A Propensity Score Matching Analysis
}

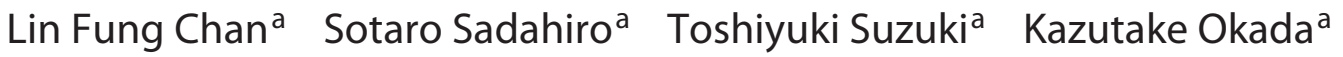 \\ Hiroshi Miyakita $^{a}$ Seiichiro Yamamoto $^{a}$ Hiroshi Kajiwara $^{b}$ \\ aDepartment of Surgery, School of Medicine, Tokai University, Isehara, Japan; 'bepartment of Pathology, School of \\ Medicine, Tokai University, Isehara, Japan
}

\section{Keywords}

Tissue-infiltrating lymphocytes · Colon cancer · Prognostic factor

\begin{abstract}
Background: In patients with colorectal cancer, the rate of recurrence increases as the histologic stage progresses. However, the prediction of recurrence in individual patients is difficult. Many studies have reported on the relation between outcomes and tissue-infiltrating lymphocytes (TILs). The aim of our study was to clarify the relation between TILs and oncologic outcomes in patients with colon cancer using propensity score matching analysis. Methods: The study group comprised 513 patients with colon cancer who received curative resection. By using propensity score matching for sex, age, tumor location, T stage, N stage, histologic type, and adjuvant therapy as conventional prognostic factors, 61 patients with recurrence and 61 patients with no recurrence were selected. Hematoxylin-eosin staining and immunohistochemical staining using CD3, CD8, CD4, and FoxP3 were performed for lymphocytes in the primary tis-
\end{abstract}

sue. The results were evaluated separately in the whole tumor, the central part, and the invasive margin. Results: The median follow-up period was 53 months. Among the 513 patients, 70 had recurrence and 443 had no recurrence. In the comparison of outcomes between the 61 patients with recurrence and the 61 patients with no recurrence, univariate analysis showed that the disease-free survival rate was significantly higher among the patients with positive TILs in the whole tumor and in the invasive margin $(p=0.016$ and $p=0.012$, respectively) and with CD8+ cells in the central part $(p=0.039)$ than among those with negative results. A multivariate analysis showed that TILs in the invasive margin (hazard ratio $1.81 ; 95 \%$ confidence interval, $1.03-3.05 ; p=$ 0.037 ) and CD8+ cell density in the central part (hazard ratio 1.76; $95 \%$ confidence interval, $1.07-2.93 ; p=0.023$ ) were prognostic factors that were independent from conventional prognostic factors. Conclusions: In patients with curatively resected colon cancer, TILs in the invasive margin and CD8+ cell density in the central part may be prognostic factors suggesting host antitumor immune response.

(C) 2020 The Author(s)

Published by S. Karger AG, Basel

$\begin{array}{ll}\text { karger@karger.com } & \text { (c) 2020 The Author(s) } \\ \text { Pww.karger.com/ocl } & \text { Published by S. Karger AG, Basel } \\ \text { This article is licensed under the Creative Commons Attribution- } \\ \text { NonCommercial-NoDerivatives 4.0 International License (CC BY- } \\ \text { NC-ND) (http://www.karger.com/Services/OpenAccessLicense). } \\ \text { Usage and distribution for commercial purposes as well as any dis- } \\ \text { tribution of modified material requires written permission. }\end{array}$

Sotaro Sadahiro, MD, PhD

Department of Surgery, School of Medicine, Tokai University 143 Shimokasuya

Isehara 259-1193 (Japan)

sadahiro@is.icc.u-tokai.ac.jp 


\section{Introduction}

In the USA, colorectal cancer is the third most common cancer and the third leading cause of cancer-related death [1]. In Japan, colorectal cancer is the third leading cause of cancer-related death and the most common type of cancer [2]. Stage I, II, and III colorectal cancers can be curatively resected in nearly all patients. In one study, the recurrence rate was $5 \%$ with stage I disease, $12 \%$ with stage II disease, and $33 \%$ with stage III disease [3]. As the histologic grade of the tumor progresses, the rate of recurrence thus increases. In patients with stage III and high-risk stage II disease, adjuvant chemotherapy should be indicated.

However, the rate of recurrence in individual patients is difficult to accurately predict. Several studies reported that risk factors for recurrence included T4 invasion, the number of retrieved lymph nodes, tumor perforation, obstruction, and poorly differentiated adenocarcinoma, but these factors remain to be established [4-6]. As for lymphocyte infiltration in the cancer tissue, prognostic factors have been reported to be the density of CD8+ T cells and the ratio of $\mathrm{CD} 8+$ cells to FoxP3+ cells in patients with ovarian cancer; the densities of CD8+ and CD20+ cells in patients with non-small cell lung cancer; and the densities of CD8+ and FoxP3+ cells in patients with hepatocellular carcinoma [7-9]. In patients with colorectal cancer, the densities of CD3+, CD4+, CD8+, CD56+, and CD57+ cells have been reported to be related to survival rates [10-12]. However, the clinical significance of the densities of CD3+, CD4+, CD8+, CD56+, and CD57+ cells as prognostic factors has not yet been established.

We therefore performed a propensity score matching analysis using clinicopathological risk factors as covariates to examine the relation between tissue-infiltrating lymphocytes (TILs) and outcomes in patients with recurrence and in patients without recurrence following curative resection.

\section{Subjects and Methods}

\section{Patient Selection and Data Extraction}

Among patients with pathologic stage I, II, and III colon cancers who underwent curative surgery in Tokai University Hospital between January 2005 and December 2015, we studied 513 patients with colon cancer after excluding patients with cancer of the splenic flexure, a boundary between the right side and the left side of the colon. Data extracted from the patient records included baseline characteristics (sex and age) and primary tumor characteristics (tumor location, pathologic $\mathrm{T}$ stage, pathologic $\mathrm{N}$ stage, pathologic TNM stage, and histologic type) at initial surgery, as well as postoperative adjuvant chemotherapy.

\section{Postoperative Surveillance}

Patients with colon cancer who received curative resection entered our surveillance program and were followed up on an outpatient basis. All patients underwent follow-up examinations every 3-4 months for the first 2 years, every $6-12$ months from 3 to 5 years, and annually thereafter. For most patients, follow-up evaluations at each visit included medical history-taking, physical examinations, measurement of serum carcinoembryonic antigen levels, chest radiography, and abdominal ultrasonography. Chest and abdominal CT scans were performed every 6 months for up to 5 years and annually thereafter. Barium enema or colonoscopy was performed during the first, third, and fifth years. Abnormal physical findings or laboratory results mandated further screening by abdominal and pelvic CT, chest CT, and magnetic resonance imaging, as required [13-15].

\section{Propensity Score Matching}

To eliminate differences in conventional clinicopathological prognostic factors between patients with recurrence and those with no recurrence, propensity score matching was performed using sex, age, tumor location (right-sided colon cancer including tumors arising from the cecum, ascending colon, hepatic flexure, and transverse colon, or left-sided colon cancer including tumors arising from the descending colon, sigmoid colon, and rectosigmoid), pathologic Tumor-Node-Metastasis (TNM) stage (TNM classification of the Union for International Cancer Control and the American Joint Committee on Cancer) [16, 17], histologic type, and the presence or absence of adjuvant chemotherapy as covariates. Propensity score matching analysis was performed using a caliper width of 0.2 and nearest neighbor matching at a 1:1 ratio.

\section{Histologic Measurements of TILs}

After propensity score matching, we evaluated TILs and lymphocyte infiltration in the primary tissue of 122 patients. The TIL counts were quantitatively evaluated using hematoxylin-eosin (H-E)-stained tumor tissue specimens. The subtypes of TILs were evaluated by immunohistochemical staining with the surface markers of lymphocytes (CD3, CD4, CD8, and FoxP3) as follows. Formalin-fixed paraffin-embedded sections were used. Antibodies for the pan-T-cell marker CD3 (ready to use, clone 2GV6; Roche, Basel, Switzerland), helper T-cell marker CD4 (diluted 1:100, clone 4B12; DAKO, Glostrup, Denmark), cytolytic T-cell marker CD8 (diluted 1:40, C8/144B; DAKO), and regulatory T-cell marker FoxP3 (diluted 1:100, clone SP97; Thermo Fisher Scientific, Waltham, MA, USA) were used as the primary monoclonal antibodies.

An avidin-biotin-peroxidase complex method with diaminobenzidine as a chromogen was used according to the manufacturer's instructions. For CD3 and CD8 immunostaining, the VENTANA Discovery ULTRA Slide Staining System (Roche Diagnostics, Risch-Rotkreuz, Switzerland) was used. For CD4 and FoxP3 immunostaining, the Leica BOND-MAX Fully Automated Immunohistochemistry System (Leica Biosystems, Nussloch, Germany) was used. VENTANA Cell Conditioning Solution (CCI) was used
Tissue-Infiltrating Lymphocytes as a Predictive Factor in Colon Cancer
Oncology 2020;98:680-688

DOI: $10.1159 / 000506706$ 

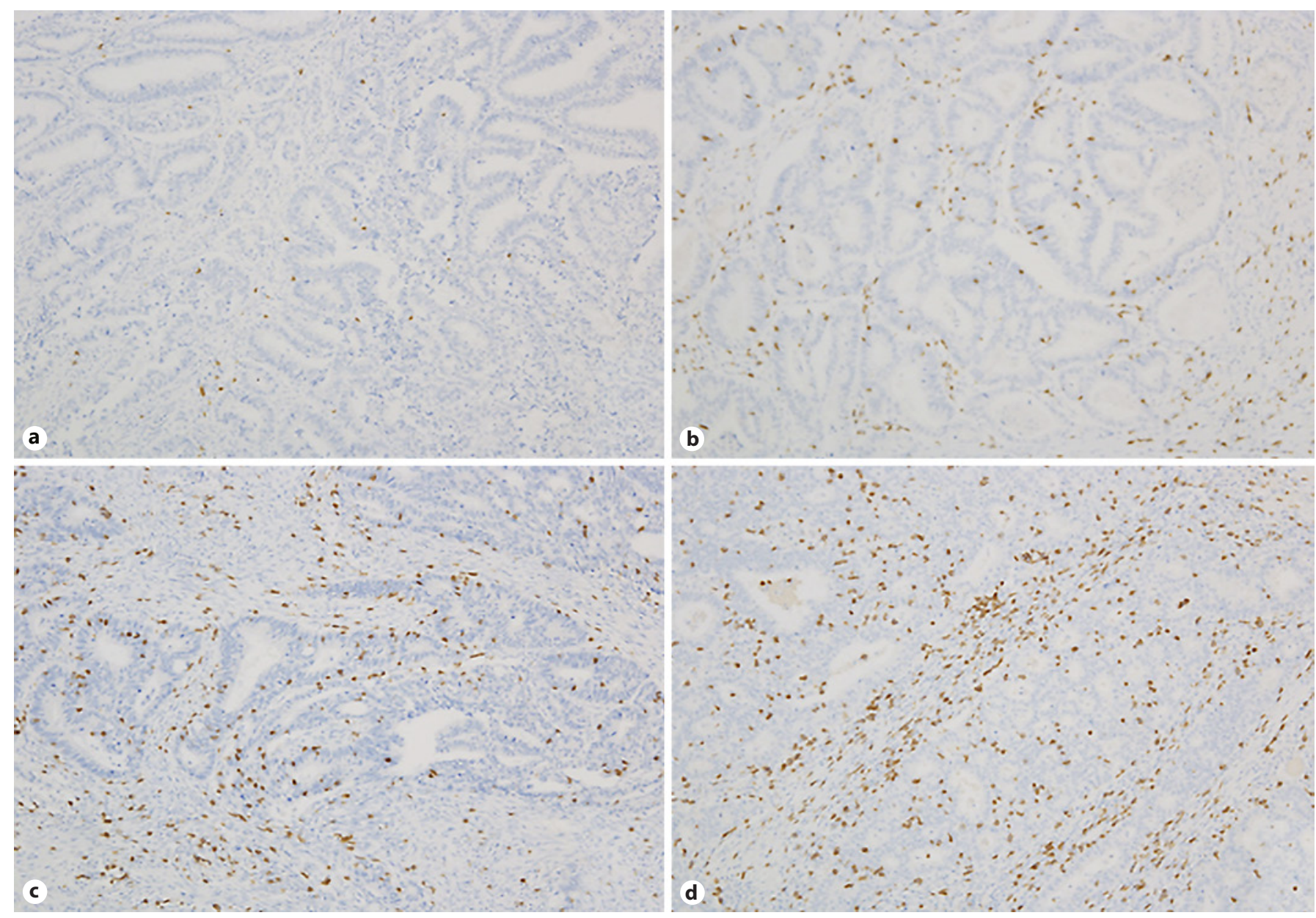

Fig. 1. a Absence or a few CD8+ cells infiltrating the central part (grade 0). b Mild infiltration of CD8+ cells in the central part (grade 1). c Moderate infiltration of CD8+ cells in the central part (grade 2). d Strong infiltration of CD8+ cells in the central part (grade 3).

for $60 \mathrm{~min}$ for CD3 and CD8 staining. BOND Epitope Retrieval Solution 2 (AR9640) was used for $20 \mathrm{~min}$ for CD4 and FoxP3 staining.

The results were evaluated in three parts consisting of the whole tumor, the central part of the tumor, and the invasive margin. The degree of infiltration of TILs (cell density) was graded according to a 4 -grade scale: grade 0 , no infiltration; grade 1 , a small amount of infiltration; grade 2, a moderate amount of infiltration; and grade 3 , a large amount of infiltration. Grade 0 or 1 was regarded as negative, and grade 2 or 3 was regarded as positive (Fig. 1).

On staining, FoxP3+ cells were found to be widely scattered. Therefore, to examine the density of FoxP3+ cells, the number of stained lymphocytes was counted in 10 views at a magnification of $\times 400$. Using receiver operating characteristic curves, 60 FoxP3+ cells per 10 views were decided to be the cutoff level; $\geq 60$ FoxP3+ cells were regarded as positive, and $<60$ FoxP $3+$ cells were regarded as negative.

\section{Statistical Analysis}

All statistical analyses were performed using JMP version 13 software (SAS Institute Japan, Tokyo, Japan). Categorical variables were analyzed using Fisher's exact test, and continuous variables were analyzed using Student's $t$ test. The best cutoff points were obtained by receiver operating characteristic curve analysis.

The disease-free survival (DFS) rate was calculated by the Kaplan-Meier method. Multivariate analysis was performed using a Cox proportional-hazards model. $p$ values of $<0.05$ were considered to indicate statistical significance.

\section{Results}

The median follow-up period was 53 months (range $7-125$ ). Among the 513 patients, 70 had recurrence and 443 had no recurrence. After propensity score matching, $61 \mathrm{pa}-$ 
Table 1. Relationship between recurrence and baseline patient characteristics before and after propensity score (PS) matching

\begin{tabular}{|c|c|c|c|c|c|c|}
\hline & \multicolumn{3}{|c|}{ Before PS matching $(n=513)$} & \multicolumn{3}{|c|}{ Recurrence after PS matching $(n=122)$} \\
\hline & $\begin{array}{l}\text { recurrence } \\
(n=70)\end{array}$ & $\begin{array}{l}\text { no recurrence } \\
(n=443)\end{array}$ & $p$ & $\begin{array}{l}\text { recurrence } \\
(n=61)\end{array}$ & $\begin{array}{l}\text { no recurrence } \\
(n=61)\end{array}$ & $p$ \\
\hline \multicolumn{7}{|l|}{ Sex, $n(\%)$} \\
\hline Male & $33(7)$ & $243(47)$ & \multirow[t]{3}{*}{0.25} & $28(23)$ & $33(27)$ & \multirow[t]{3}{*}{0.47} \\
\hline Female & $37(7)$ & $200(39)$ & & $33(27)$ & $28(23)$ & \\
\hline Age, years & $69 \pm 9.1$ & $68 \pm 11.2$ & & $70 \pm 8.6$ & $71 \pm 11.1$ & \\
\hline \multicolumn{7}{|l|}{ Location of the tumor ${ }^{1}$} \\
\hline Right side of colon & $34(7)$ & $229(45)$ & \multirow[t]{2}{*}{0.7} & $30(25)$ & $34(28)$ & \multirow[t]{2}{*}{0.59} \\
\hline Left side of colon & $36(7)$ & $214(41)$ & & $31(25)$ & $27(22)$ & \\
\hline \multicolumn{7}{|l|}{ Pathological T stage } \\
\hline $\mathrm{T} 1$ & $3(1)$ & $115(22)$ & \multirow[t]{4}{*}{$<0.01$} & $3(2)$ & $3(2)$ & \multirow[t]{4}{*}{0.96} \\
\hline $\mathrm{T} 2$ & $7(1)$ & $69(13)$ & & $7(6)$ & $7(6)$ & \\
\hline T3 & $33(7)$ & $188(37)$ & & $31(25)$ & $28(23)$ & \\
\hline $\mathrm{T} 4$ & $27(5)$ & $71(14)$ & & $20(17)$ & $23(19)$ & \\
\hline \multicolumn{7}{|l|}{ Pathological N stage } \\
\hline N0 & $33(7)$ & $327(64)$ & \multirow[t]{3}{*}{$<0.01$} & $30(25)$ & $32(26)$ & \multirow[t]{3}{*}{0.97} \\
\hline N1 & $21(4)$ & $95(18)$ & & $19(16)$ & $17(13)$ & \\
\hline N2 & $16(3)$ & $21(4)$ & & $12(10)$ & $12(10)$ & \\
\hline \multicolumn{7}{|l|}{ Pathological TNM stage } \\
\hline I & $8(2)$ & $158(31)$ & \multirow[t]{3}{*}{$<0.01$} & $8(7)$ & $6(5)$ & \multirow[t]{3}{*}{0.69} \\
\hline II & $24(5)$ & $168(33)$ & & $21(17)$ & $25(20)$ & \\
\hline III & $38(7)$ & $117(22)$ & & $32(26)$ & $30(25)$ & \\
\hline \multicolumn{7}{|l|}{ Histologic type } \\
\hline Well & $26(5)$ & $213(42)$ & \multirow[t]{4}{*}{0.18} & $25(20)$ & $23(19)$ & \multirow[t]{4}{*}{0.71} \\
\hline Moderate & $39(8)$ & $212(41)$ & & $34(28)$ & $33(27)$ & \\
\hline Poor & $2(0.4)$ & $6(1)$ & & $1(1)$ & $1(1)$ & \\
\hline Mucinous & $3(0.6)$ & $12(2)$ & & $1(1)$ & $4(3)$ & \\
\hline \multicolumn{7}{|c|}{ Postoperative adjuvant chemotherapy } \\
\hline Positive & $25(5)$ & $135(26)$ & \multirow[t]{2}{*}{0.41} & $35(29)$ & $28(23)$ & \multirow[t]{2}{*}{0.28} \\
\hline Negative & $45(9)$ & $308(60)$ & & $26(21)$ & $33(27)$ & \\
\hline
\end{tabular}

Values denote $n(\%)$ or mean \pm SD. ${ }^{1}$ Right-sided colon cancers included tumors arising from the cecum, ascending colon, hepatic flexure, and transverse colon, while left-sided colon cancers included tumors arising from the descending colon and sigmoid colon.

tients in each group were analyzed. No significant differences were observed with regard to baseline characteristics (sex, age, tumor location, pathologic $\mathrm{T}$ stage, pathologic $\mathrm{N}$ stage, pathologic TNM stage, histologic type, and adjuvant chemotherapy) between the groups (Table 1).

\section{TILs on H-E Staining and Density of Lymphocytes on Immunohistochemical Staining}

The positivity rates in the whole tumor were $77 \%$ for TILs, $96 \%$ for CD3 + cell density, 78\% for CD4+ cell density, $93 \%$ for CD8+ cell density, and 56\% for FoxP3+ cell density. The positivity rates in the central part on $\mathrm{H}-\mathrm{E}$ staining were $49 \%$ for TILs, $67 \%$ for CD3+ cells, $54 \%$ for
CD $4+$ cells, and $49 \%$ for CD $8+$ cells. The positivity rates in the invasive margin on $\mathrm{H}-\mathrm{E}$ staining were $77 \%$ for TILs, $96 \%$ for CD3+ cells, $74 \%$ for CD $4+$ cells, and $90 \%$ for CD8+ cells (Fig. 2).

\section{Univariate Analysis of Clinicopathological Variables in Relation to DFS}

Table 2 shows the results of univariate analysis of the relation of DFS to clinicopathological factors and TILassociated factors that have been reported to be related to outcomes. There was no significant relation of DFS to sex, age, tumor location, histologic type, or the presence or absence of adjuvant therapy. With regard to the 

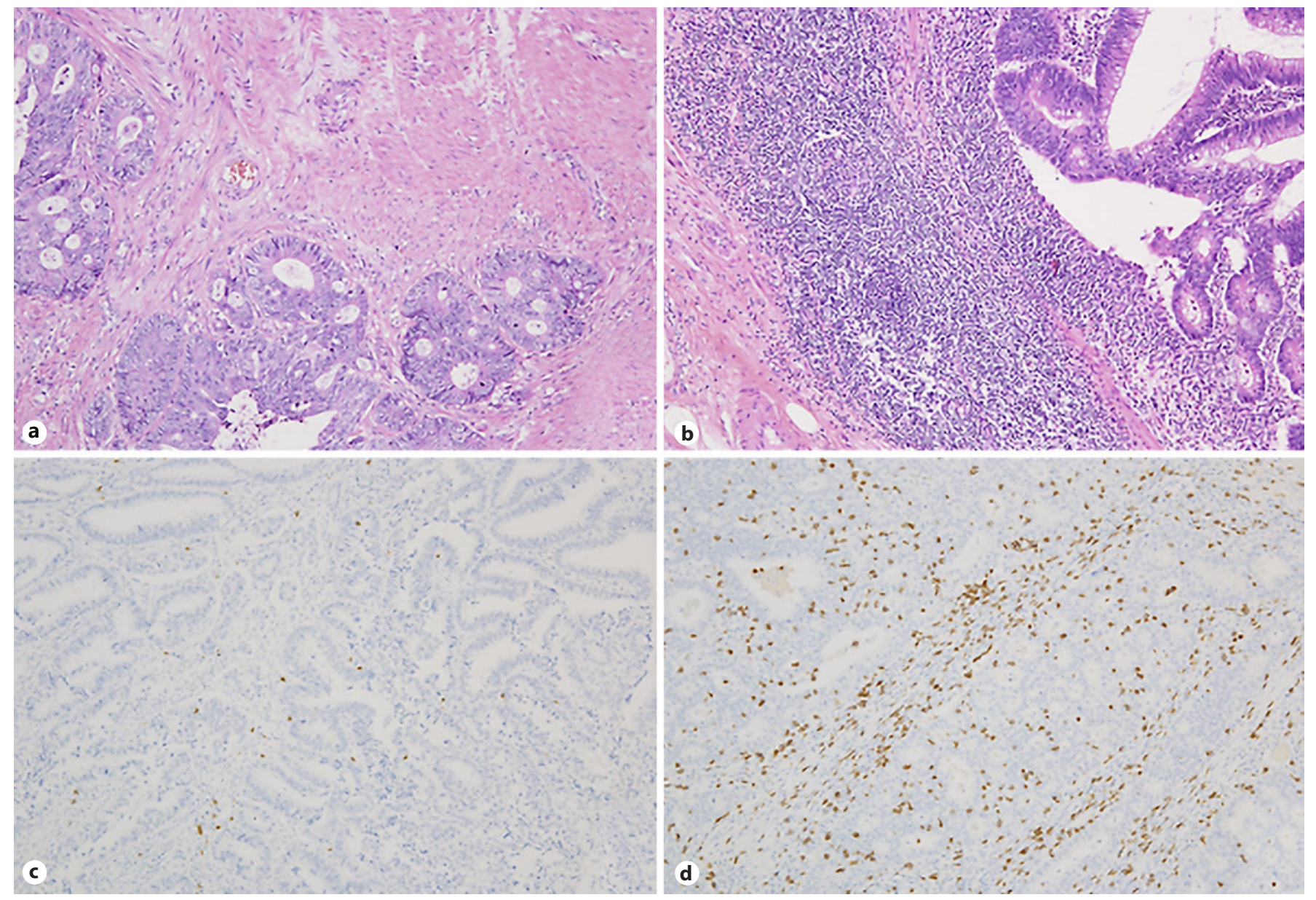

Fig. 2. Examples of stained sections showing different patterns of T-cell infiltration in the microenvironment of colon tumors. a Minor T-cell infiltration in the invasive margin. b Strong infiltration of T cells in the invasive margin. c A few CD8+ cells infiltrating the central part. d Strong infiltration of CD8+ cells in the central part.

whole tumor, on H-E staining, the 5-year DFS rate was significantly higher among patients who were positive for TILs (48\%) than among those who were negative for TILs $(27 \%)(p=0.016)$. There was no relation between DFS and the densities of $\mathrm{CD} 3+, \mathrm{CD} 4+, \mathrm{CD} 8+$, or FoxP3+ cells. Regarding the central part, the 5-year DFS rate was significantly higher among patients with a positive density of CD8+ cells (51\%) than among those with a negative density $(34 \%)(p=0.039)$. There was no relation of DFS to TILs and the densities of CD3+ or CD4+ cells.

As regards the invasive margin, the 5-year DFS rate was significantly higher among patients who were positive for TILs (48\%) than among those who were negative for TILs $(26 \%)(p=0.012)$. There were no differences in the densities of $\mathrm{CD} 3+, \mathrm{CD} 4+$, or $\mathrm{CD} 8+$ cells between patients with positive results and those with negative results.

\section{Multivariate Analysis of Clinicopathological Variables} in Relation to DFS

Using clinicopathological risk factors and factors found to be related to DFS on univariate analysis (TILs in the invasive margin on $\mathrm{H}-\mathrm{E}$ staining and CD8+ cell density in the central part), multivariate analysis was performed using a Cox proportional-hazards model (Table 3). TILs in the invasive margin were associated with a hazard ratio of 1.81 (95\% confidence interval, 1.03-3.05; $p=0.037)$. CD8 + cell density in the central part was associated with a hazard ratio of 1.76 (95\% confidence in- 
Table 2. Univariate analysis of the parameters associated with DFS

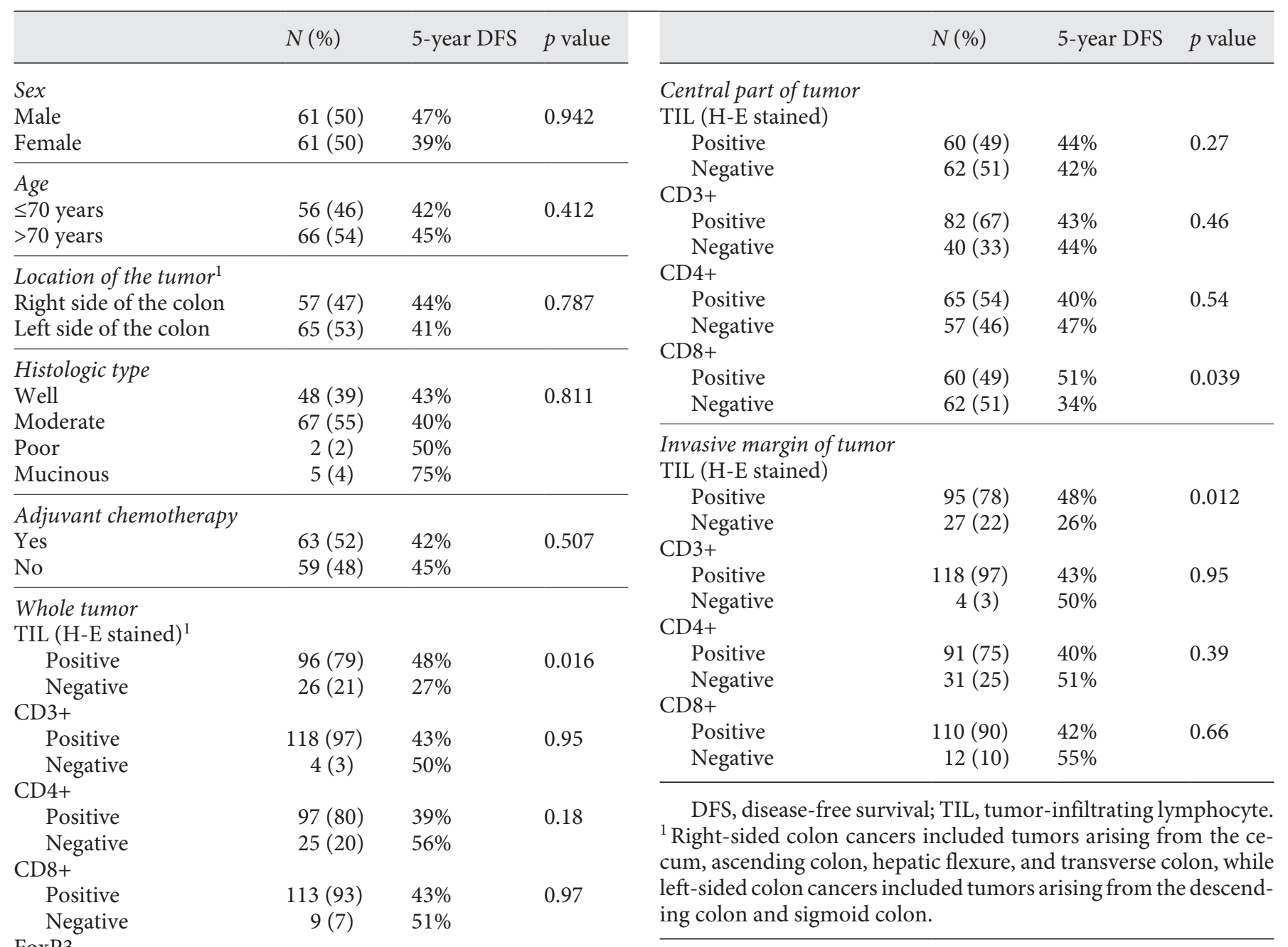

terval, $1.07-2.93 ; p=0.023)$. TILs in the invasive margin and CD8+ cell density in the central part were independent prognostic factors.

\section{Discussion}

In clinical practice, the outcomes of patients with curatively resected colorectal cancer can be predicted on the basis of the TNM classification. However, patients with stage IIB or IIC disease have poorer outcomes than those with stage IIIA disease. Therefore, factors other than the previously used $\mathrm{T}$ stage and $\mathrm{N}$ stage are consid- ered to determine outcomes [18]. Stage II disease was diagnosed in about $30-40 \%$ of patients who underwent surgery for colon cancer [19]. Some studies reported that adjuvant therapy can improve outcomes in patients with stage II disease and risk factors for recurrence. However, risk factors for recurrence have yet to be established [20, 21].

Host immune response has been recognized to be an important determinant of the outcomes of human tumors [22]. In patients with colorectal cancer, infiltration of inflammatory cells is related to survival rates, independently of histologic tumor grades. In addition to tumorassociated macrophages, dendritic cells, and neutrophils, 
Table 3. Multivariate analysis of parameters associated with disease-free survival

\begin{tabular}{|c|c|c|c|c|c|c|c|c|}
\hline \multicolumn{9}{|l|}{ Sex } \\
\hline Male & $61(50)$ & $47 \%$ & 1.0 & Reference & & 1.0 & Reference & \\
\hline Female & $61(50)$ & $39 \%$ & 1.03 & $0.63-1.68$ & 0.88 & 0.99 & $0.61-1.61$ & 0.98 \\
\hline \multicolumn{9}{|l|}{ Age } \\
\hline$>70$ years & $66(54)$ & $45 \%$ & 1.15 & $0.72-1.86$ & 0.54 & 1.06 & $0.66-1.72$ & 0.78 \\
\hline \multicolumn{9}{|l|}{ Location of the tumor ${ }^{1}$} \\
\hline Right side of the colon & $57(47)$ & $44 \%$ & 1.0 & Reference & & 1.0 & Reference & \\
\hline Left side of the colon & $65(53)$ & $41 \%$ & 1.33 & $0.83-2.16$ & 0.22 & 1.26 & $0.79-2.02$ & 0.32 \\
\hline \multicolumn{9}{|l|}{ Histologic type } \\
\hline \multicolumn{9}{|l|}{ Adjuvant chemotherapy } \\
\hline Yes & $63(52)$ & $42 \%$ & 1.0 & Reference & & 1.0 & Reference & \\
\hline No & $59(48)$ & $45 \%$ & 0.93 & $0.58-1.48$ & 0.77 & 0.95 & $0.60-1.52$ & 0.85 \\
\hline \multicolumn{9}{|l|}{ Invasive margin of tumor } \\
\hline \multicolumn{9}{|l|}{ TIL (H-E stained) } \\
\hline Positive & $95(78)$ & $48 \%$ & 1.0 & Reference & & & & \\
\hline Negative & $27(22)$ & $27 \%$ & 1.81 & $1.03-3.05$ & 0.037 & & & \\
\hline \multicolumn{9}{|l|}{ Central part of tumor } \\
\hline \multicolumn{9}{|l|}{$\mathrm{CD} 8+$} \\
\hline Positive & $60(49)$ & $51 \%$ & & & & 1.0 & Reference & \\
\hline
\end{tabular}

TIL, tumor-infiltrating lymphocyte. ${ }^{1}$ Right-sided colon cancers included tumors arising from the cecum, ascending colon, hepatic flexure, and transverse colon, while left-sided colon cancers included tumors arising from the descending colon and sigmoid colon.

the presence of TILs may be an effective indicator of immune response [23]. As for subtypes of T cells, some studies reported a relation of CD3+ [24, 25], CD8+ [10, 24, 26, 27], CD45RO+ cells $[23,28]$, and FoxP3+ cells $[29,30]$ to outcomes.

To clarify the relation between TILs and outcomes, we performed propensity score matching in the present study, using previously reported clinicopathological risk factors for recurrence, and compared these factors between the two groups, with no significant differences. Consequently, we found that TILs on H-E staining and the density of CD8+ cells in the central part were determinant prognostic factors. Our results differ from those of previous studies. Many studies reported that CD8+ cells in the central part and the invasive margin are related to prognosis $[10,24,26]$. Other studies reported that
CD8+ cells only in the central part are related to prognosis. The results remain controversial [27]. Our results reconfirm that host immune response is an important determinant prognostic factor of human cancer. However, further studies are required to determine appropriate methods for evaluating immune response and the part of the tumor to be assessed.

\section{Conclusions}

We performed propensity score matching using conventional clinicopathological factors in patients with curatively resected colon cancer to examine the relation between TILs and outcomes and found that TILs in the invasive margin and the density of CD8+ cells in the central 
part may be independent prognostic factors. These results suggest a close relation between the host's immune response and prognosis.

\section{Statement of Ethics}

This study was approved by the Institutional Review Board of Tokai University (16R-267), and all patients provided written informed consent.

\section{Disclosure Statement}

The authors have no potential conflicts of interest to declare.

\section{Funding Sources}

There was no funding for this study.

\section{Author Contributions}

Conception and design: L.F. Chan and S. Sadahiro; provision of study materials or patients: L.F. Chan, S. Sadahiro, T. Suzuki, K. Okada, and H. Miyakita; collection and assembly of data: L.F. Chan, K. Okada, and T. Suzuki; data analysis and interpretation: L.F. Chan, S. Sadahiro, H. Kajiwara; manuscript writing: L.F. Chan and S. Sadahiro; final approval of the manuscript: L.F. Chan, S. Sadahiro, T. Suzuki, K. Okada, H. Miyakita, S. Yamamoto, and H. Kajiwara.

\section{References}

1 Siegel RL, Fedewa SA, Miller KD, GodingSauer A, Pinheiro PS, Martinez-Tyson D, et al. Cancer statistics for Hispanics/Latinos, 2015. CA Cancer J Clin. 2019 Jan;65(6):45780.

2 Center for Cancer Control and Information Services, National Cancer Center, Japan. Projected Cancer Statistics, 2018 [accessed 2019 Oct 23]. Available from: https://ganjoho.jp/ en/public/statistics/short_pred.html.

3 Osterman E, Glimelius B. Recurrence risk after up-to-date colon cancer staging, surgery, and pathology: analysis of the entire Swedish population. Dis Colon Rectum. 2018 Sep; 61(9):1016-25.

4 André T, Boni C, Navarro M, Tabernero J, Hickish T, Topham C, et al. Improved overall survival with oxaliplatin, fluorouracil, and leucovorin as adjuvant treatment in stage II or III colon cancer in the MOSAIC trial. J Clin Oncol. 2009 Jul;27(19):3109-16.

5 Labianca R, Nordlinger B, Beretta GD, Brouquet A, Cervantes A; ESMO Guidelines Working Group. Primary colon cancer: ESMO Clinical Practice Guidelines for diagnosis, adjuvant treatment and follow-up. Ann Oncol. 2010 May;21(Suppl 5):v70-7.

6 National Comprehensive Cancer Network. Clinical Practice Guidelines in Oncology, version 2 [accessed 2019 Oct 20]. 2018. Available from: https://www.nccn.org/professionals/ physician_gls/pdf/colon.pdf.

7 Fu J, Xu D, Liu Z, Shi M, Zhao P, Fu B, et al. Increased regulatory $\mathrm{T}$ cells correlate with CD8 T-cell impairment and poor survival in hepatocellular carcinoma patients. Gastroenterology. 2007 Jun;132(7):2328-39.

8 Al-Shibli KI, Donnem T, Al-Saad S, Persson M, Bremnes RM, Busund LT. Prognostic effect of epithelial and stromal lymphocyte infiltration in non-small cell lung cancer. Clin Cancer Res. 2008 Aug 15;14(16):5220-7.
9 Leffers N, Gooden MJ, de Jong RA, Hoogeboom BN, ten Hoor KA, Hollema $\mathrm{H}$, et al. Prognostic significance of tumor-infiltrating T-lymphocytes in primary and metastatic lesions of advanced stage ovarian cancer. Cancer Immunol Immunother. 2009 Mar;58(3): $449-59$.

10 Naito Y, Saito K, Shiiba K, Ohuchi A, Saigenji K, Nagura H, et al. CD8+ T cells infiltrated within cancer cell nests as a prognostic factor in human colorectal cancer. Cancer Res. 1998 Aug;58(16):3491-4.

11 Menon AG, Janssen-van Rhijn CM, Morreau H, Putter H, Tollenaar RA, van de Velde CJ, et al. Immune system and prognosis in colorectal cancer: a detailed immunohistochemical analysis. Lab Invest. 2004 Apr;84(4): 493-501.

12 Deschoolmeester V, Baay M, Van Marck E, Weyler J, Vermeulen P, Lardon F, et al. Tumor infiltrating lymphocytes: an intriguing player in the survival of colorectal cancer patients. BMC Immunol. 2010 Apr;11:19.

13 Sadahiro S, Suzuki T, Ishikawa K, Nakamura T, Tanaka Y, Masuda T, et al. Recurrence patterns after curative resection of colorectal cancer in patients followed for a minimum of ten years. Hepatogastroenterology. $2003 \mathrm{Sep}-$ Oct;50(53):1362-6.

14 Sadahiro S, Suzuki T, Maeda Y, Yurimoto S, Yasuda S, Makuuchi H, et al. Detection of carcinoembryonic antigen messenger RNA-expressing cells in peripheral blood 7 days after curative surgery is a novel prognostic factor in colorectal cancer. Ann Surg Oncol. 2007 Mar; 14(3):1092-8.

15 Sadahiro S, Suzuki T, Tanaka A, Okada K, Kamata H. Hematogenous metastatic patterns of curatively resected colon cancer were different from those of stage IV and autopsy cases. Jpn J Clin Oncol. 2013 Apr;43(4):444-7.
16 Amin MB, Greene FL, Edge SB, Compton CC, Gershenwald JE, Brookland RK, et al. The Eighth Edition AJCC Cancer Staging Manual: continuing to build a bridge from a population-based to a more "personalized" approach to cancer staging. CA Cancer J Clin. 2017 Mar;67(2):93-9.

17 Brierley JD, Gospodarowicz MK, Wittekind C. TNM classification of malignant tumors, 8th edition. Wiley-Blackwell; 2017.

18 Kim HS, Kim KM, Lee SB, Kim GR, Han YD, Cho MS, et al. Clinicopathological and biomolecular characteristics of stage IIB/IIC and stage IIIA colon cancer: insight into the survival paradox. J Surg Oncol. 2019 Sep;120(3): 423-30.

19 Morris M, Platell C, McCaul K, Millward M, van Hazel G, Bayliss E, et al. Survival rates for stage II colon cancer patients treated with or without chemotherapy in a population-based setting. Int J Colorectal Dis. 2007 Aug;22(8): $887-95$.

20 Mamounas E, Wieand S, Wolmark N, Bear $\mathrm{HD}$, Atkins JN, Song K, et al. Comparative efficacy of adjuvant chemotherapy in patients with Dukes' B versus Dukes' C colon cancer: results from four National Surgical Adjuvant Breast and Bowel Project adjuvant studies (C01, C-02, C-03, and C-04). J Clin Oncol. 1999 May;17(5):1349-55.

21 Wolmark N, Colangelo L, Wieand S. National Surgical Adjuvant Breast and Bowel Project trials in colon cancer. Semin Oncol. $2001 \mathrm{Feb}$; 28(1 Suppl 1):9-13.

22 Hanahan D, Weinberg RA. Hallmarks of cancer: the next generation. Cell. 2011 Mar; 144(5):646-74.

23 Roxburgh CS, McMillan DC. The role of the in situ local inflammatory response in predicting recurrence and survival in patients with primary operable colorectal cancer. Cancer Treat Rev. 2012 Aug;38(5):451-66.
Tissue-Infiltrating Lymphocytes as a Predictive Factor in Colon Cancer 
24 Nagtegaal ID, Marijnen CA, Kranenbarg EK, Mulder-Stapel A, Hermans J, van de Velde CJ, et al. Local and distant recurrences in rectal cancer patients are predicted by the nonspecific immune response; specific immune response has only a systemic effect - a histopathological and immunohistochemical study. BMC Cancer. 2001;1:7.

25 Flaherty DC, Lavotshkin S, Jalas JR, TorisuItakura H, Kirchoff DD, Sim MS, et al. Prognostic utility of immunoprofiling in colon cancer: results from a prospective, multicenter nodal ultrastaging trial. J Am Coll Surg. 2016 Jul;223(1):134-40.
26 Canna K, McArdle PA, McMillan DC, McNicol AM, Smith GW, McKee RF, et al. The relationship between tumour T-lymphocyte infiltration, the systemic inflammatory response and survival in patients undergoing curative resection for colorectal cancer. $\mathrm{Br} \mathrm{J}$ Cancer. 2005 Feb;92(4):651-4.

27 Richards CH, Roxburgh CS, Powell AG, Foulis AK, Horgan PG, McMillan DC. The clinical utility of the local inflammatory response in colorectal cancer. Eur J Cancer. 2014 Jan; 50(2):309-19.

28 Kong JC, Guerra GR, Pham T, Mitchell C, Lynch AC, Warrier SK, et al. Prognostic impact of tumor-infiltrating lymphocytes in primary and metastatic colorectal cancer: a systematic review and meta-analysis. Dis Colon Rectum. 2019 Apr;62(4):498-508.
29 Correale P, Rotundo MS, Del Vecchio MT, Remondo C, Migali C, Ginanneschi C, et al. Regulatory (FoxP3+) T-cell tumor infiltration is a favorable prognostic factor in advanced colon cancer patients undergoing chemo or chemoimmunotherapy. J Immunother. 2010 May;33(4):435-41.

30 Ling A, Edin S, Wikberg ML, Öberg A, Palmqvist R. The intratumoural subsite and relation of CD8+ and FOXP3+ T lymphocytes in colorectal cancer provide important prognostic clues. Br J Cancer. 2014 May; 110(10): 2551-9. 